\title{
The polymerase chain reaction: An overview and development of diagnostic PCR protocols at the LCDC
}

\author{
National Laboratory of Enteric PATHOgens, BurEau of Microbiology, \\ LABORATORY CENTRE FOR DISEASE CONTROL
}

$\mathrm{T}$ HE DEVELOPMENT IN THE LATE 1980S OF A PROPRIETARY method for in vitro amplification of specific DNA or RNA sequences by the polymerase chain reaction (PCR) has revolutionized molecular biology. The PCR has many applications in biology and affords tremendous early diagnostic potential in many areas of medicine and infectious diseases. The key to the success of the PCR in diagnosis resides in its ability to amplify regions within a single molecule of DNA which may have etiologic significance.

The PCR can readily produce more than a million copies of a specific DNA or RNA sequence in a simple three-step cycling process. The initial step involves the denaturation of double-stranded DNA to separate the complementary strands, and the second step allows for the annealing of primers to the dissociated DNA strands. Third, the primers participate in an extension reaction catalyzed by a thermostable DNA polymerase, and the cycle is then repeated. The PCR reaction uses two primers complementary to and hybridizing with opposite strands of the DNA with one to the left (5') and one to the right $\left(3^{\prime}\right)$ of the target sequence to be amplified. If the template is an RNA sequence, a DNA copy (cDNA) must first be synthesized using a reverse transcriptase before the PCR is initiated. The DNA copies or 'amplicons' are typically produced in a few hours after approximately 303 to 5 min cycles in which enzymatic extension theoretically doubles the amount of DNA from the previous cycle. Although different DNA polymerases have been used in PCR applications, the most convenient is the thermostable polymerase 'Taq' isolated from Thermus aquaticus. Taq polymerase is capable of withstanding the high temperatures required to denature
DNA, and has permitted optional automation of the technique using programmable thermal cyclers now available from a variety of commercial sources.

The most common method of visualizing amplicons generated in the PCR procedure is gel electrophoresis in polyacrylamide or agarose, followed by ethidium bromide staining. The observed sizes of the amplified fragment should be identical to those predicted from the known nucleotide sequence. Nonspecific hybridization of the primers to sequences other than those targeted usually generates amplification fragments of sizes different from the desired amplicon. Because such nontargeted amplification is not uncommon, methods such as ultraviolet spectroscopy and fluorometry, which only indicate an increase in the total amount of DNA present, should be avoided as a means of detection. In order to ensure that the target sequence has been amplified, it is recommended that the specificity be tested by probing a Southern blot of the analytical gel, or dot-blots, with labelled probes nested between the PCR primers and representing a portion of the amplified sequence, or that restriction endonuclease digestions specific for sites within the amplicon should be used. For all PCR applications, sample preparation techniques and amplification and detection methods need to be optimized during the research and developmental phase.

It is recognized that DNA polymerases do not duplicate DNA with complete fidelity, and nucleotide misincorporation does occur. In nature most of these polymerases possess a proofreading activity which will remove any misincorporated nucleotides and replace them with the correct base. Commercially prepared 
polymerases often lack this proofreading function, as is the case for Taq polymerase, and a base substitution error rate of one in 10.000 bases polymerized has been estimated for Taq (1). The potential for nucleotide misincorporation has necessitated modifications in established techniques when sequencing data is to be obtained subsequent to PCR amplification. Maximum fidelity can be achieved by a combination of optimal in vitro deoxynucleoside triphosphate concentrations, $\mathrm{pH}$, divalent metal cations, ionic strength and temperature conditions. Deviations from these established optima may result in anomalous amplification products.

False positive amplifications are a potential problem with all diagnostic PCR applications, and the most serious source arises from the carryover of DNA from a previous amplification of the same target sequence rather than from sample-to-sample contamination during contemporaneous processing. As a result, precau tions must be in place in the PCR laboratory to avoid this carryover. Essential safeguards include physical separation of pre- and post PCR amplifications, aliquoted reagents, positive displacement pipettes, and judicious selection of controls, in addition to meticulous technique when one is using a variety of laboratory equipment and supplies.

Fortunately, a wide variety of clinical specimens is suitable for genotypic analysis in PCR applications. These specimens include whole blood or white blood cells, other body fluids such as urine or feces, clinical swabs, dried smears and paraffin-embedded tissues. Tissues fixed in methanol or 50\% ethanol are superior to those fixed in formalin in that the yield of DNA is higher and less degradation of nucleic acids occurs. Heparinized or citrated blood has been used for DNA analysis, in addition to air-dried blood smears on slides optionally fixed with ethanol or methanol.

Research applications of PCR technology are numerous. A partial listing would include direct genomic cloning of DNA or cDNA, genetic fingerprinting of forensic samples, the analysis of allelic sequence variations, and direct nucleotide sequencing. The PCR has the potential to replace many conventional diagnostic techniques for infectious and genetic diseases in clinical medicine. The PCR is currently being used to study genetic diseases such as hemophilia, cystic fibrosis, retinoblastoma, Huntington's disease, sickle cell anemia and beta-thalassemia, von Willebrand's disease. Leber's optic neuropathy, muscular dystrophy, phen ylketonuria, Tay-Sachs, and alpha-1-antitrypsin defi ciency. The PCR can also be used to screen for point mutations in the insulin gene, detect a single lymphoma cell in the presence of $10^{6}$ normal cells, study chromosomal translocations, detect growth hormone gene deletions, and determine human lymphocyte antigen (HLA) class II gene polymorphism.

The PCR has an advantage over the competing technology of DNA hybridization in that the sensitivity is sufficient to allow the direct detection of microbial DNA in a high percentage of known positive pathological specimens, a quality not always found in DNA hybridization methods. This genotypic technique, however, also detects gene-harbouring strains, independent of gene expression. Hence, a positive result in the PCR is only indicative of the presence of the targeted gene sequence and does not reflect the viability or pathogenic toxic activities of the organism in the specimen. The PCR may supplement growth amplification protocols which can often fail to detect virulent strains present at low levels in pathological or food samples. Frequently, nonpathogenic strains of the same genus or species overgrow the pathogens, and strains may readily lose plasmid- or phage-mediated virulence factors. The PCR allows specific enzymatic replication of targeted gene fragments and, since cell growth and replication are not required, both injured and viable cells will be detected and identified with equal facility. In foods, an indicator of dead cells yields valuable information as to the quality of the food, but may not be indicative of a health hazard. The PCR can be performed using whole bacterial cells without extraction of nucleic acids and, coupled with pre-enrichment growth before the PCR, dilutes out DNA not being biologically duplicated, thus permitting the identification of organisms in samples containing numbers of pathogenic bacteria undetectable by other routine methods. The identification of target genes related to virulence by the PCR offers a very specific, sensitive, relatively rapid and inexpensive alternative to traditional in vitro assays, which depend on adequate gene expression for reliability and sensitivity. The interested reader is referred to more detailed procedural information in the laboratory manuals (1-3) and recent review articles on PCR (4-18).

PCR applications for the diagnosis of infectious diseases occurred first with viral infections, for which early detection is particularly important. PCR results can be obtained within one day of receipt of specimens in the laboratory. There are now specific and sensitive PCR protocols published for the detection and typing of human genital papillomaviruses, human immunodeficiency virus types 1 and 2 , human T cell lymphotropic virus type I, hepatitis viruses A, B and C, several serotypes of human enteroviruses, human herpes virus and rotaviruses, human parvovirus B19, rhinovirus, pseudorabies virus, rubella virus, paramyxoviruses causing mumps and measles, cytomegalovirus and Epstein-Barr virus. The PCR has also been used to establish the viral etiology in both enteroviral meningitis and viral myocarditis.

PCR procedures have been combined with probes targeting Escherichia coli and legionella genes and have been applied to the detection of bacterial pathogens in environmental water samples. This combination of techniques provides the necessary sensitivity and specificity required for monitoring bacterial pathogens 
in environmental water. To date, PCR protocols have also been published for acute typhus infection, detection of shigella in feces, toxigenic $E$ coli, total coliform bacteria, Legionella pneumophila, Mycobacterium species, Bordetella pertussis, Mycoplasma pneumoniae, Borrelia burgdorferi, Treponema pallidum, Coxiella burnettii, Candida albicans, Rickettsia rickettsii, Trypanosoma congolense and Trypanosoma brucei subspecies. All of these infectious diseases can be diagnosed with increased sensitivity and specificity in a shorter or equal time frame and at substantially less cost by PCR than by conventional techniques.

The application of PCR technology to the detection and diagnosis of bacterial pathogens has been a recent priority at the Laboratory Centre for Disease Control (LCDC). Dr D Russell Pollard from the National Laboratory for Special Pathogens in the Bureau of Microbiology was one of the first researchers in Canada to develop PCR protocols to detect pathogenic microbes associated with human disease. Since his premature and untimely death in June of 1990, his colleagues have continued the revolutionary work that was initiated in his laboratory. Current research and development at the LCDC follows the initiative established by Dr Pollard and is focused on PCR diagnostic protocols targeting virulence and pathogenicity factors associated with a variety of infectious agents important in human disease.

To date, we have developed several PCR protocols. The first was for the specific detection of Chlamydia

\section{REFERENCES}

1. Erlich HA, Gibbs R, Kazazian HH Jr. Polymerase chain reaction. In: Current Communications in Molecular Biology. New York: Cold Spring Harbor Laboratory Press, 1989:6.

2. Innes MA, Gelfand DH, Sninsky JJ, White TJ. PCR Protocols, A Guide to Methods and Applications. San Diego: Academic Press Inc, 1990.

3. Sambrook J, Fritsch EF, Maniatis T. In vitro amplification of DNA by the polymerase chain reaction. In: Molecular Cloning. A Laboratory Manual, 2nd edn. New York: Cold Spring Harbor Laboratory Press, 1989;14.2-35.

4. Anderson R. Molecular considerations for the laboratory diagnosis of Japanese encephalitis virus. Southeast Asian J Trop Med Public Health 1989;20:605-10.

5. Eisenstein BI. The polymerase chain reaction. A new method of using molecular genetics for medical diagnosis. N Engl J Med 1990;322:178-83.

6. Fox RI, Dotan I, Compton T, Fei HM. Hamer M, Saito I. Use of DNA amplification methods for clinical diagnosis in autoimmune diseases. J Clin Lab Anal 1989:3:378-87.

7. Goossens M. Recent developments in the diagnosis of the hemoglobin disorders. Nouv Rev Fr Hematol 1990;32:63-5.

8. Grompe M. Gibbs RA. Chamberlain JS, Caskey CT. Detection of new mutation disease in man and mouse. Mol Biol Med 1989;6:511-21 species in both laboratory samples of infected McCoy cells and clinical specimens. In a collaborative project between the LCDC and the Cadham provincial laboratory in Manitoba, parallel testing of this PCR and Abbott Chlamydiazyme ${ }^{\mathrm{TM}}$ procedures was recently completed on 274 clinical specimens with very promising results.

In other work, a battery of verotoxin-specific primers has resulted in PCR protocols to specifically detect and distinguish the genes for VT1, VT2, and VTe in human and nonhuman isolates of verotoxigenic $E$ coli. One of the PCR protocols developed at the LCDC in the verotoxin study clearly distinguished the very closely related genes coding for VT2 and VTe. Additionally, a very significant contribution focused on differentiation of the virtually identical genes for the shigatoxin of Shigella dysenteriae 1 and E coli VT1. The verotoxin PCR protocols are currently being applied to the complete genotypic analysis of verotoxigenic $E$ coli isolated from retail meats and verotoxigenic $E$ coli associated with pediatric hemolytic uremic syndrome.

The LCDC has just published a study on the detection of the aerolysin gene in clinical isolates of Aeromonas hydrophila by the PCR, and these primers should have application as a species-specific virulence probe to distinguish beta-hemolytic strains of A hydrophila and Aeromonas sobria. Another major investigation, also recently completed at the LCDC, describes the detection of genes by the PCR for enterotoxins A to E, exfoliative toxins $\mathrm{A}$ and $\mathrm{B}$, and toxic shock syndrome toxin-1 in Staphylococcus aureus.

9. Husson RN, Comeau AM, Hoff R. Diagnosis of human immunodeficiency virus infection in infants and children. Pediatrics 1990;86:1-10.

10. Jackson JB. The polymerase chain reaction in transfusion medicine. Transfusion 1990;30:51-7.

1 1. Kazazian HH Jr. The thalassemia syndromes: Molecular basis and prenatal diagnosis in 1990. Semin Hematol 1990:27:209-28.

12. Macintyre EA. The use of the polymerase chain reaction in haematology. Blood Rev 1989;3:201-10.

13. Ratner L, Vander Heyden N, Paine E, et al. Familial adult T-cell leukemia/lymphoma. Am J Hematol 1990;34:215-22.

14. Reiss J, Cooper DN. Application of the polymerase chain reaction to the diagnosis of human genetic disease. Hum Genet 1990;85:1-8.

15. Rodu B. The polymerase chain reaction: The revolution within. Am J Med Sci 1990;299:210-6.

16. Rosenblatt JD, Zack JA, Chen IS, Lee H. Recent advances in detection of human T-cell leukemia viruses type I and type II infection. Nat Immun Cell Growth Regul 1990;9:143-9.

17. Sninsky JJ, Kwok S. Detection of human immunodeficiency viruses by the polymerase chain reaction. Arch Pathol Lab Med 1990:1 14:259-62.

18. Sommer SS, Cassady JD, Sobell JL, Bottema CD. A novel method for detecting point mutations or polymorphisms and its application to population screening for carriers of phenylketonuria. Mayo Clin Proc 1989;64:1361-72. 


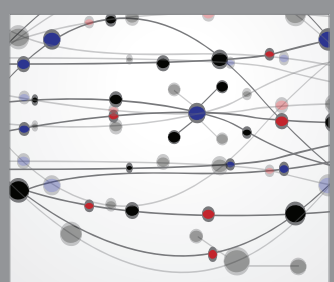

The Scientific World Journal
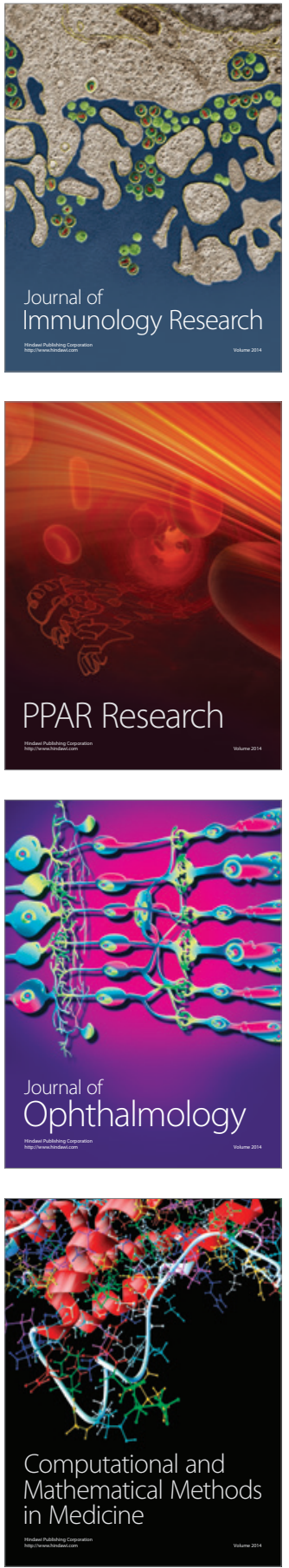

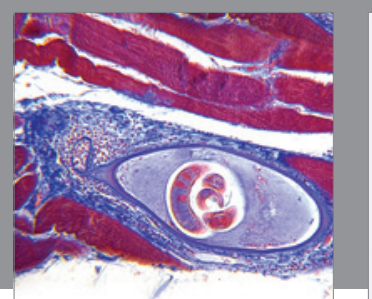

Gastroenterology Research and Practice

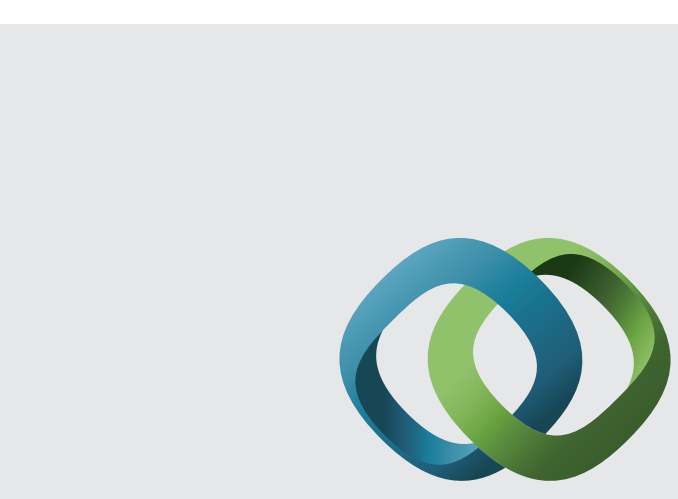

\section{Hindawi}

Submit your manuscripts at

http://www.hindawi.com
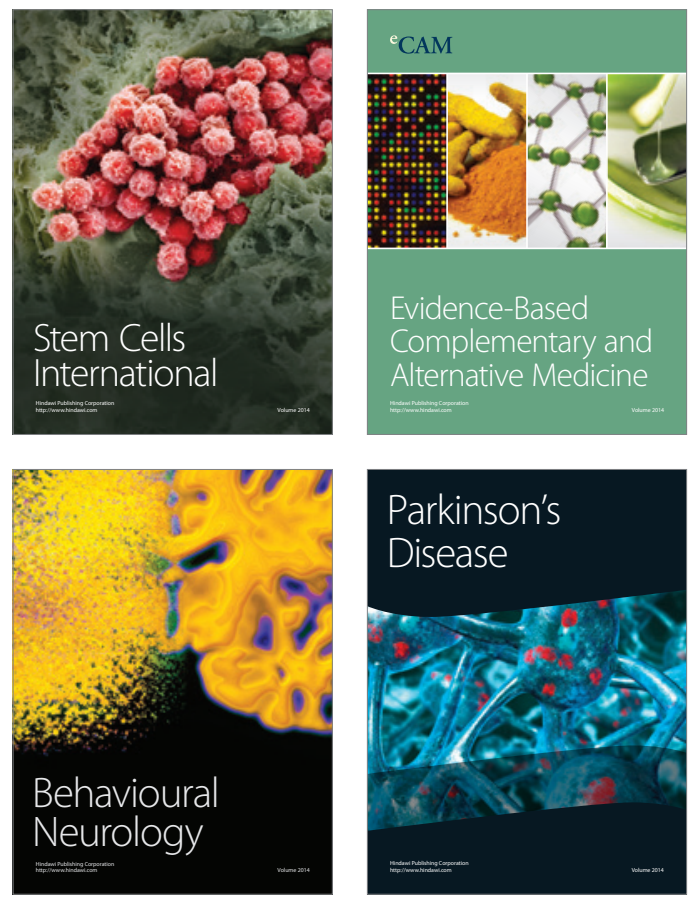
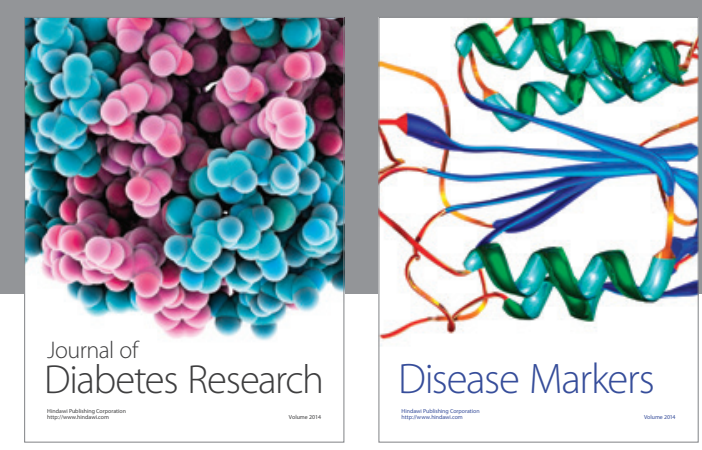

Disease Markers
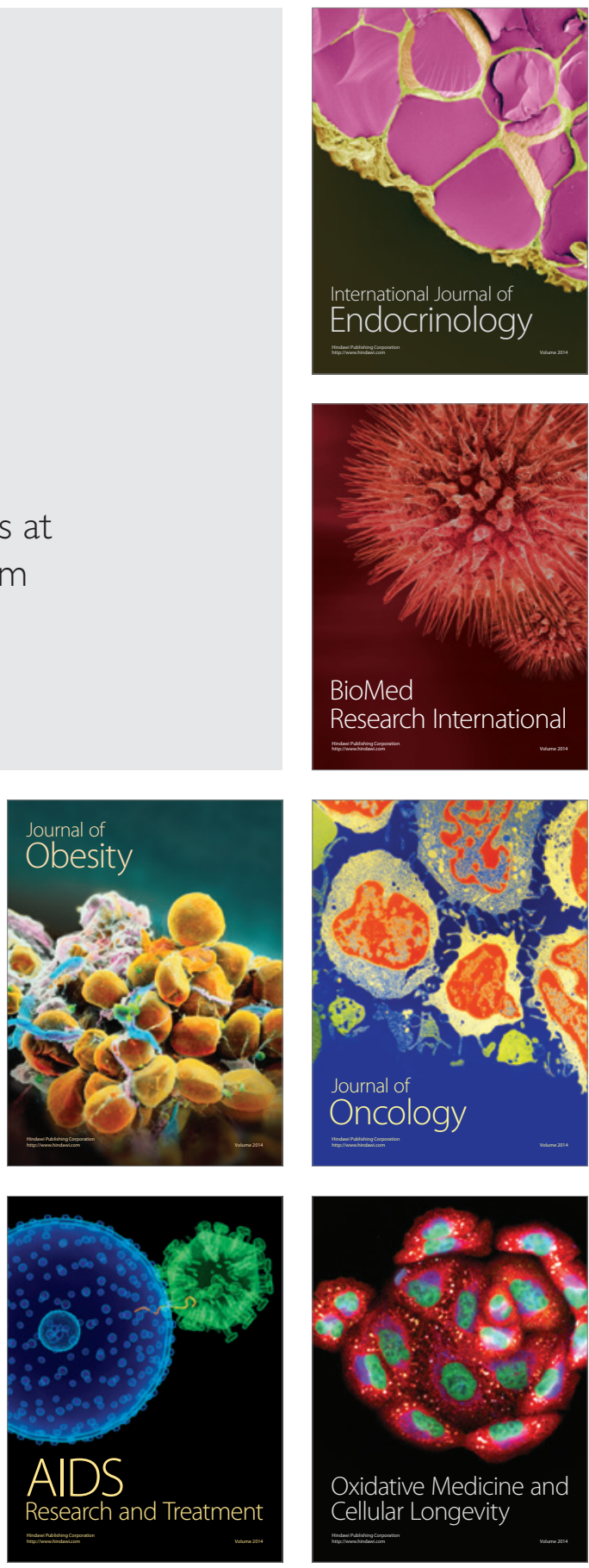